\title{
Nadir Görülen Bir Over Tümörü: Sklerozan Stromal Tümör ${ }^{*}$
}

\author{
Seçil HASDEMİ ${ }^{1}$, Fatma ÖZ ATALAY ${ }^{2}$, Mehmet Aral ATALAY ${ }^{3}$ \\ 1 Mardin Midyat Devlet Hastanesi, Tıbbi Patoloji Bölümü, Mardin. \\ 2 Bursa Uludağ Üniversitesi Tıp Fakültesi, Tıbbi Patoloji Anabilim Dalı, Bursa. \\ 3 Özel Jimer Hastanesi, Kadın Hastalıkları ve Doğum Kliniği, Bursa.
}

\section{ÖZET}

Sklerozan stromal tümör (SST) over seks kord stromal tümörleri arasında yer alan oldukça nadir görülen benign bir stromal tümördür. Bu olgu sunumunda sağ overde SST saptanan hastanın, radyolojik bulguları ve histopatolojik özellikleri literatür eşliğinde kısaca tartışılmıştır. 23 yaşında kadın hasta, pelvik ağrı şikayeti ile başvurduğu dış merkezde yapılan abdominal ultrasonografisinde sağ adnekste kistik ve solid komponenti olan kitle lezyon saptanması üzerine ileri tanı ve tedavi için hastanemiz kadın doğum polikliniğine yönlendirildi. Cinsiyet değiştirme istemi de olan hastaya yapılan laboratuvar incelemelerinde herhangi bir hormonal anormallik saptanmadı. Kitlenin frozen incelemesi sonrasında total abdominal histerektomi ve bilateral salpingoooferektomi (TAH+BSO) yapılması kararlaştırıldı. Frozen kesitlerin incelenmesi sonucu "seks kord stromal tümör" olarak değerlendirilen tümörün mikroskopik incelemesinde, kollajenöz ve ödemli hiposellüler alanlar ile hipersellüler alanların oluşturduğu psödolobüler patern, belirgin vasküler proliferasyon izlendi. Morfolojik ve immunhistokimyasal bulgular ışığında sağ overde izlenen tümör "SST" olarak tanı almıștır. Sklerozan stromal tümör olgularının büyük bir kısmı vasküler açıdan zengin solid kitle olduğundan radyolojik olarak öncelikle malign tümör olasıllı̆ı akla gelmektedir. SST’nin benign biyolojik davranışa sahip olması ve konservatif cerrahinin gerekli olduğu genç hastalarda görülmesi nedeniyle intraoperatif patolojik tanısı oldukça önemlidir.

Anahtar Kelimeler: Over. Seks Kord Stromal Tümör. Sklerozan Stromal Tümör.

Sclerosing Stromal Tumor: A Rare Case Report

\section{ABSTRACT}

Sclerosing stromal tumor (SST), an extremely rare benign stromal tumor, is a subtype of sexcord stromal tumors of the ovary. In this report, radiological and histopathological features of the case are briefly discussed in light of the literature. A 23-year-old female patient with a right adnexal mass showing cystic and solid components on abdominal ultrasonography, was referred to our center's obstetrics clinic for further diagnosis and treatment. The patient had no blood hormonal abnormalities and also had a request for gender change. Total abdominal hysterectomy with bilateral salpingo-oophorectomy was performed after intraoperative examination of the mass. The diagnosis of sex cord stromal tumor was given intraoperatively and later histopathological examination revealed a pseudolobular pattern formed by collagenous and edematous hyper-hypocellular areas and marked vascular proliferation. Morphological and immunohistochemical findings of the the right ovarian tumor was consistent with "SST". Radiologically, SSTS are diagnosed as a malignant tumor because of the most of them are highly vascular solid masses. For this reason, intraoperative histopathological examination is crucial to prevetn over-treatment, because SST has a benign biological behavior and occurs in young patients which conservative surgery is required.

Key Words: Ovary. Sex Cord Stromal Tumor. Sclerosing Stromal Tumor.

Geliş Tarihi: 27.Temmuz.2020

Kabul Tarihi: 09.Aralık.2020

* 28. Ulusal Patoloji Kongresi'nde (27-30 Ekim 2018, Ankara) poster bildiri olarak sunulmuştur.

Dr. Seçil HASDEMIR

Mardin Midyat Devlet Hastanesi,

Tıbbi Patoloji Bölümü,

Midyat, Mardin.

Tel: 05444622350

E-posta: secilalabay@gmail.com

Yazarların ORCID ID Bilgisi:

Seçil HASDEMiR: 0000-0003-1769-7484

Fatma ÖZ ATALAY: 0000-0002-7188-6115

Mehmet Aral ATALAY: 0000-0002-9685-956X
Seks kord stromal tümörler over tümörlerinin \%8'ini oluşturur. Sklerozan stromal tümör (SST) ise overin seks kord stromal tümörlerinin \% 5 'inden azını oluşturan oldukça nadir görülen bir varyantıdır ${ }^{1}$. İlk kez 1973 yılında Chalvardjian ve Scully tarafindan tanımlanmış benign over tümörleridir ${ }^{2}$. Genellikle 2. ve 3 . dekadda genç kadınlarda görülür ${ }^{3}$. Büyük çoğunluğu genç kadınlarda tek taraflı ve iyi sınırlı kitle olarak gelişim gösterir. En sık başvuru şikayeti menstrual düzensizlik ve karın ağrısıdır ${ }^{4}$. SST genellikle hormonal olarak inaktiftir. Ancak gebelik, androjenik semptomlar ve endometrium kanseri ile ilişkili bazı olgular bildirilmiştir $^{5}$. Bu olgu sunumunda sağ overinde SST 
bulunan TAH+BSO yapılmış hasta sunulmuş ve hastalığın epidemiyolojisi, radyolojik bulguları ve histopatolojik özellikleri ilgili literatür eşliğinde kısaca tartışılmıştır.

\section{Olgu Sunumu}

Cinsiyet değiştirme istemi bulunan 23 yaşında kadın hasta, pelvik ağrı nedeniyle başvurduğu dış merkezde yapılan pelvik ultrasonografisinde uterus anteriorunda 97x84mm boyutunda, santralinde kistik odaklar içeren solid lezyon 97x84 mm saptanması üzerine ileri tetkik ve tedavi amacı ile hastanemiz kadın doğum polikliniğine yönlendirildi. Çekilen pelvik manyetik rezonans görüntülemede supravezikal fossada uterustan ayrı yerleşim gösteren, büyük boyutlu, ortası nekrotik, solid karakterde kitlesel lezyon görüldü. Yapılan laboratuar incelemelerinde tümör belirteçlerinde yükselme ya da herhangi bir hormonal anormallik saptanmad. Hastanın cinsiyet değiştirme istemi de olması nedeniyle frozen eşliğinde total abdominal histerektomi ve bilateral salpingoooferektomi yapılması kararlaştırıldı. Frozen incelemeye gönderilen sağ adneksin makroskopik incelemesinde over 11,5x9x7,5 cm boyutunda, dış yüzey ve kapsülü intakt, kesit yüzü ağırlıklı olarak solid görünümde izlendi (Şekil 1A). Tümörün kesit yüzü yer yer jelatinöz kıvamda olup, içlerinde mukoid materyal bulunan kistik alanlar içermekteydi. Yer yer sarı turuncu renkte ve ortası beyaz renkteydi (Şekil 1B). Frozen kesitlerin incelenmesi sonucu "seks kord stromal tümör" olarak değerlendirildi. Hazırlanan kesitlerin mikroskopik incelemesinde, kollajenöz ve ödemli hiposellüler alanlar ile hipersellüler alanların oluşturduğu psödolobüler patern, belirgin vasküler proliferasyon izlendi. Hipersellüler alanların vakuolize sitoplazmalı yuvarlak poligonal hücreler ile daha az oranda fibroblast benzeri iğsi hücrelerden oluştuğu görülmüştür (Şekil 2). İmmunhistokimyasal incelemede tümör hücrelerinde inhibin, CD99, düz kas aktin (SMA) ve kalretinin fokal pozitif, epitelyal membran antijeni (EMA), S100 ve desmin negatif olarak saptand1 (Şekil 3). Olguya morfolojik ve immunhistokimyasal bulgular ışı̆̆ında "Sklerozan Stromal Tümör" tanıs1 verildi.

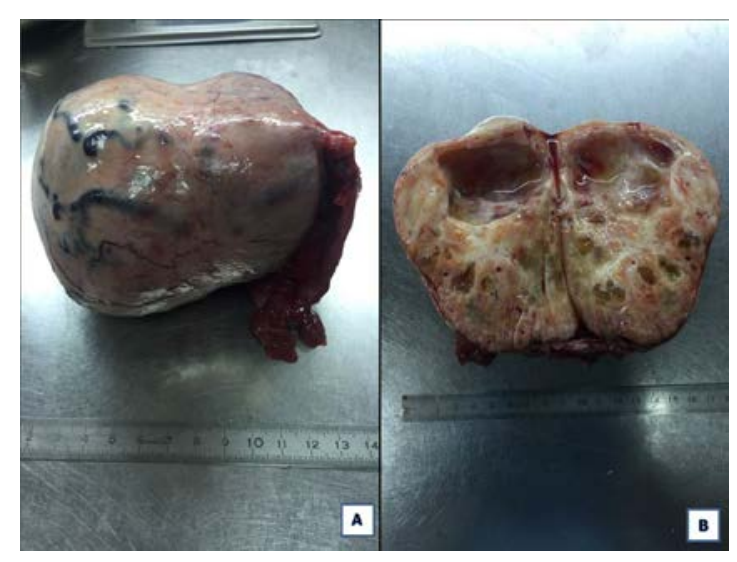

Şekil 1:

Să̆ adneksin makroskopik incelemesinde over 11,5x9x7,5 cm boyutunda, dış yüzey ve kapsülü intakt, kesit yüzü ăğlllklı olarak solid görünümde izlendi (1A). Tümörün kesit yüzü yer yer jelatinöz kıvamda olup, içlerinde mukoid materyal bulunan kistik alanlar içermekteydi. Yer yer sarı turuncu renkte ve ortası beyaz renkteydi $(1 B)$.

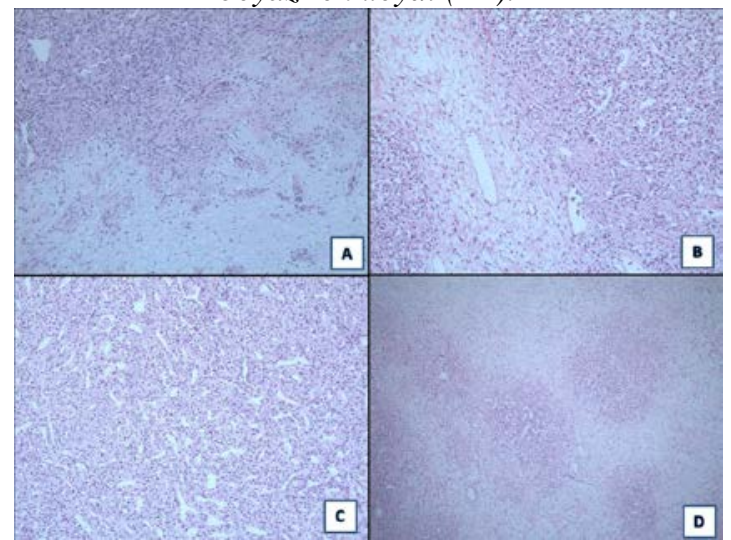

Şekil 2:

Kollajenöz ve ödemli hiposellüler alanlar ile hipersellüler alanların (2A-2B) oluşturduğu belirgin vasküler proliferasyona (2C) sahip psödolobüler patern (2D) izlendi.

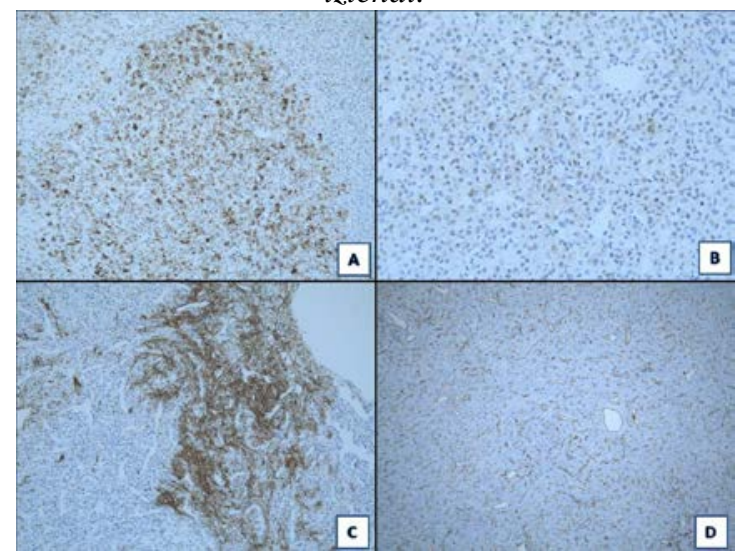

Şekil 3:

Immunhistokimyasal incelemede tümör hücrelerinde inhibin (3A),kalretinin (3B), düz kas aktin

(SMA)(3C)ve CD99 fokal pozitif, epitelyal membran antijeni (EMA) (3D), S100 ve desmin negatif olarak saptand. 


\section{Tartışma ve Sonuç}

Sklerozan Stromal Tümör Dünya Sağlık Örgütü (WHO) 2015 sinıflamasında overin seks kord stromal tümörleri arasında pür stromal tümörler başlığı adı altında yer almaktadır 6 . Oldukça nadir görülen bu tümör diğer stromal tümörlerden klinik ve histopatolojik olarak farklılık göstermektedir. Genellikle unilateral olup \%70'ten fazlası sağ tarafta yerleşim gösterir ${ }^{7}$. Büyük çoğunluğu 20-40 yaş aralığında görülür ancak literatürde postmenapozal ${ }^{8}$ ve çocukluk döneminde ${ }^{9}$ görülen olgular bildirilmiştir. Bizim olgumuz da 23 yaşında olup tümör sağ over yerleşimliydi.

SST'lerin over stromasındaki pluripotent kök hücrelerden kaynaklandığı düşünülmekte olup etiyolojisi tam olarak aydınlatılamamıştır ${ }^{10}$.

Klinik olarak en sık karın ağrısı, menstrüel düzensizlik ve pelvik kitlelerle prezente olurlar. Genellikle hormonal olarak inaktiftirler ancak hormon sentezleyen vakalar da bildirilmiştir. Bunlar da östrojenik ya da DHEA'dan türeyen androjenik tiptedir ${ }^{12}$. Premenarşal dönemde ve gebelikte maskülinizasyon bulguları ile prezente olan vakalar bildirilmiştir ${ }^{13}$. Kaygusuz ve ark.' larının yayınlamış olduğu 7 olguluk seride ise 3 olgu gebelik sırasında tanı almıştır ${ }^{5}$. Özdemir ve ark.' 'ları literatür derlemesinde 9 virilize SST olgusundan bahsetmiştir ${ }^{10}$. Bizim olgumuz da karın ağrısı şikayeti ve cinsiyet değiştirme isteği ile hastanemize basvurmuştur.Radyolojik olarak SST olgularının büyük bir kısmı vasküler açıdan zengin solid kitle olduğundan radyolojik olarak öncelikle malign tümör olasılığ1 akla gelmektedir. Ultrasonografide düzensiz, kalın septalı hipoekoik ekojeniteli multilokule kistik ya da solid kitleler şeklinde görülürler. Magnetik rezonans görüntülemede ise T2 agırlıklı imajlarda tipik olarak santrali belirgin hiperintens periferi daha az yoğunlukta sinyal vermesi fibrom/tekom grubu diğer stromal over tümörlerinden ayrımda önemlidir ${ }^{14}$. Bizim olgumuzda da ultrasonografide santralinde kistik odaklar içeren solid lezyon ve MR görüntülemede periferinde belirgin vaskülarizasyonun olduğu ortası nekrotik kitle izlendi.

Makroskobik olarak ortalama $10 \mathrm{~cm}$ çapında düzgün sınırlı, sarı renkte, yer yer ödemli ve kistik alanların görüldüğü solid kitleler şeklinde görülürler ${ }^{15}$. SST overin diğer stromal tümörlerine göre karakteristik histopatolojik özelliklere sahiptir. Bu tümörler kollajenöz ve ödemli hiposellüler alanlar ile hipersellüler alanların oluşturduğu psödolobüler patern ile hemanjioperistomatöz görünümde bazıları dallanan ince duvarlı belirgin vasküler proliferasyon içerir. Hipersellüler alanlarda vakuolize sitoplazmalı yuvarlak poligonal luteinize teka hücreleri ile daha az oranda fibroblast benzeri kollajen üreten iğsi hücrelerden oluşan iki hücre tipi izlenir. Mitoz nadirdir ${ }^{6}$. Bizim olgumuzda tümör $11,5 \mathrm{~cm}$ çapında olup benzer histopatolojik görünüme sahipti.
Histopatolojik olarak ayırıcı tanıda tekom, fibrom, Krukenberg tümörü ve masif ovaryan ödem yer alır. Fibrom ve tekom genellikle ileri yaş kadınlarda görülür ve lobulasyon paterni fibromlarda görülmez. Tekomlarda ise genellikle tek tip luteinize hücreler ve hyalen plaklar izlenir. Krukenberg tümörü taklit eden taşlı yüzük benzeri hücre varlığında epitelyal belirteçler ve müsin negatifliği ayırıcı tanıda önemli role sahiptir.

İmmunohistokimyasal olarak tümör hücreleri özellikle luteinize hücreler kalretinin pozitiftir. İnhibin, Desmin, SMA, Vimentin, CD10, östrojen reseptör (ER) ve progesteron reseptör (PR) ile de pozitiflik görülebilir ancak epitelyal markerlar negatiftir ${ }^{16}$. Bizim olgumuzda da inhibin, CD99, SMA ve kalretinin ile fokal pozitiflik izlendi. Park ve ark.'larının SST'de TFE3 ekspresyonunu araştırdıkları çalışmalarında \%77.8 oranında orta ve şiddetli, \%22,2 oranında vakada hafif TFE3 ekspresyonu saptamışlardır. Yine aynı çalışmada luteinize tekom ve fibrom vakalarının hiçbirinde TFE3 ekspresyonu izlenmemiştir ${ }^{17}$.

Bizim hastamızda olduğu gibi cinsiyet değiştirme istemi olan hastalarda ayrıntılı psikiyatrik ve jinekolojik muayene ile hormon profili değerlendirilmesi büyük önem taşımaktadır. Hastamızda tedavi öncesi hormonal anormallik saptanmadı ancak bu gibi olgularda sklerozan stromal tumor gibi virilizan over tümörleri de akılda tutulmalı ve dışlanmalıdır.

Radyolojik olarak genellikle malign tümörler ile kar1şabilen SST'nin benign biyolojik davranışa sahip bir tümör olması ve konservatif cerrahinin gerekli olduğu genç hastalarda görülmesi nedeniyle intraoperatif patolojik tanısının doğru verilmesi hasta yönetimi açısından oldukça önemlidir.

\section{Kaynaklar}

1. Atram M, Anshu, Sharma S, Gangane N. Sclerosing stromal tumor of the ovary. Obstet Gynecol Sci. 2014;57(5):405-8.

2. Chalvardjian A, Scully RE. Sclerosing stromal tumors of the ovary. Cancer 1973;31:664-70.

3. Furukawa S, Kanno K, Kojima M, Ohara M, Soeda S, Suzuki S, Watanabe T, Nishiyama H, Honda T, Fujimori K. Sclerosing stromal tumor of the ovary treated with 2-incision total laparoscopic cystectomy. Int J Surg Case Rep. 2015; 9: 72-74.

4. Youm HS, Cha DS, Han KH, Park EY, Hyon NN, Chong Y. A case of huge sclerosing stromal tumor of the ovary weighing 10 $\mathrm{kg}$ in a 71-year-old postmenopausal woman. J Gynecol Oncol. 2008;19(4):270-4.

5. Kaygusuz EI, Cesur S, Cetiner H, et al. Sclerosing Stromal Tumour in Young Women: Clinicopathologic and Immunohistochemical Spectrum. J Clin Diagn Res. 2013 Sep; 7(9): 19325.

6. McCluggage WG, Kiyokawa T, Staats PN, Young RH. Sex cord-stromal tumours-pure stromal tumours: Sclerosing Adenosis In: Kurman RJ, Carcangiu ML, Herrington CS, Young RH eds. World Health Organization Classification of Tumours of Female Reproductive Organs. Lyon, France: IARC Press, 2014(4);46-7. 


\section{S. Hasdemir, ark.}

7. Marelli G, Carinelli S, Mariani A, Frigerio L, Ferrari A. Sclerosing stromal tumor of the ovary. Report of eight cases and review of the literature. Eur J Obstet Gynecol Reprod Biol. 1998 Jan;76(1):85-9.

8. Lee CM, Lim S, Cho HY, Lee JS, Shin JW. Sclerosing Sromal Tumor of the Ovary in Postmenopausal Women: A Report of Two Cases. J Menopausal Med. 2015;21(2):115-9.

9. Squillaro AI1, Zhou S2, Thomas SM3,4, Kim ES1,5. A 10 Month-Old Infant Presenting With Signs of Precocious Puberty Secondary to a Sclerosing Stromal Tumor of the Ovary in the Absence of Hormonal Elevation. Pediatr Dev Pathol. 2018 Dec 21:1093526618819605. doi: 10.1177/1093526618819605.

10. Ozdemir O, Sarı ME, Sen E, Kurt A, Ileri AB, Atalay CR. Sclerosing stromal tumour of the ovary: A case report and the review of literature. Niger Med J. 2014;55(5):432-7.

11. Khanna M, Khanna A, Manjari M. Sclerosing stromal tumor of ovary: a case report. Case Rep Pathol. 2012;2012:592836.

12. Momtahan M, Akbarzadeh-Jahromi M, Najib FS, Namazi N. Different Presentations of Five Rare Cases of Sclerosing Stro- mal Tumor of the Ovary. Indian J Surg Oncol. 2018 Dec;9(4):581-584.

13. Park SM, Kim YN, Woo YJ, et al. A sclerosing stromal tumor of the ovary with masculinization in a premenarchal girl. Korean J Pediatr. 2011;54(5):224-7.

14. Naidu A, Chung B, Simon M, Marshall I. Bilateral Sclerosing Stromal Ovarian Tumor in an Adolescent. Case Rep Radiol. 2015;2015:271394.

15. Jaime Prat. Ovarian Sex Cord-Stromal and Steroid Cell Tumors: Sclerosing Stromal Tumor In: Mutter GL, Prat J eds. Pathology of The Female Reproductive Tract. Elsevier, 2014 (3);654-5.

16. Lim GSD, Oliva E. Sex Cord Stromal Tumors of the Ovary: Sclerosing Stromal Tumor In: Soslow RA, Tornos C eds. Diagnostic Pathology of Ovarian Tumors. Springer, 2011; 206-7.

17. Park CK, Kim HS. Clinicopathological Characteristics of Ovarian Sclerosing Stromal Tumor with an Emphasis on TFE3 Overexpression. Anticancer Res. 2017 Oct;37(10):5441-7. 